\title{
Finding gaps: \\ An assessment of infection control needs in China
}

\author{
Xiaoyan Song ${ }^{1,2}$, Yinghong $\mathrm{Wu}^{3}$, Jing Zhou ${ }^{4}$ \\ ${ }^{1}$ Department of Paediatrics, The George Washington University, \\ School of Medicine and Health Sciences, Washington, \\ ${ }^{2}$ Division of Infectious Diseases, Children's National Medical Centre, Washington DC \\ ${ }^{3}$ Beijing People's Hospital, Beijing, P.R. China; \\ ${ }^{4}$ BioMerieux China Limited, Beijing, P.R. China
}

doi: 10.3396/ijic.V7i4.028.11

\begin{abstract}
Despite that infection control (IC) practice in China had advanced rapidly, little was known about staffing qualification and status of IC programs. The aim of this study was to describe characteristics of IC professionals (ICPs) and to identify opportunities for improving IC practice in China. A cross-sectional study was conducted by surveying ICPs attending national conferences in 2010. The survey consisted of 17 questions ranged from professional training, years of practices, to educational needs. Eight hundred eighty individuals from hospitals located in 32 of 34 provinces and autonomous regions in China responded to the survey. Of these respondents, $45 \%$ had five or more years IC experience. Their professional education included nursing (59.2\%), medicine $(31.6 \%)$, and public health $(8.8 \%)$. Hand hygiene $(81 \%)$, prevention of multi-drug resistant organisms $(60 \%)$, and outbreak management $(53 \%)$ were considered top priorities. Respondents primarily relied on results of the bi-annual prevalence study conducted in their hospitals and personal experience to determine priorities and risks of healthcare associated infections (HAIs). Staff collaboration (81.5\%) and leadership support (61.0\%) were viewed as the most important factors contributing to successes of HAI prevention. Nearly all (95.6\%) respondents favoured more continuing education.
\end{abstract}

This study revealed that China had highly trained and experienced ICPs, but it remained critical to empower them to practice evidence-based IC. Focused training could be one of effective means to achieve the goals.

\section{Key words}

Infection control, China

\section{Corresponding author}

Division of Infectious Disease, Children's National Medical Centre

Department of Paediatrics, George Washington University Medical Centre

Email: xsong@cnmc.org 


\section{Introduction}

Over the past 30 years, investigators in the United States had undertaken a number of studies that evaluated staffing level, ${ }^{1,2}$ infrastructure, ${ }^{1,3}$ activities, ${ }^{1,4}$ and processes $^{1,5}$ essential for hospital epidemiology and infection control programs in U.S. healthcare facilities. These studies had generated invaluable evidences that promoted effective infection control programs ${ }^{1,5,6}$ and supported hospital administrators and infection control professionals to attain necessary resources for infection control activities.

Although healthcare organizations in China were required to have an Infection Control Committee overseeing infection control activities, little was known about characteristics of infection control professionals and status of infection surveillance and control programs. Moreover in the last decade, the world witnessed the emergence and spread of Severe Acute Respiratory Symptom (SARS) in 2003, ${ }^{7-9}$ pandemic novel H1N1 influenza A in 2009, and the "superbug" - Enterobacteriaceae isolates carrying metallo-Betalactamase in 2010. ${ }^{10-12}$ In addition to that these organisms could cause severe infections requiring prolonged hospitalization and increasing mortality risk, they rapidly became major threats to global health and posed significant burdens on infection prevention and control personnel. These experiences highlighted the importance of strengthening infection control programs not only nationally but also internationally. In view of these issues, we sought to describe infection control professionals (ICPs) in China and to evaluate status of infection control activities.

\section{Methods}

\section{Study Design and Population}

This was a cross-sectional study by surveying infection control professionals attending two conferences in China. The survey was first instituted among ICPS attending the $2^{\text {nd }}$ Beijing International Conference for Hospital Infection Prevention and Control in April 2010. This conference was open to all front line ICPs in hospitals surrounding Beijing area. To increase sample size for the study, the same survey was re-instituted at the Shanghai International Forum for Infection Control in June 2010. This was the largest conference for ICPs with over 1200 attendants nationwide.

\section{Survey Questions}

The survey consisted of four components with seventeen questions. The first component collected information on ICP's characteristics including education, years of ICP experience, daily activities, and hospital profile (i.e. geographic location, type and number of beds). The second component aimed to assess ICP's perception on importance of different infection control areas. Respondents were to select three most important ones out of nine areas, specifically, device associated infections, surgical site infections, outbreak detection and control, prevention and control of multidrug resistant organism (MDROs), hand hygiene, infection control in construction and renovation, emerging infectious diseases preparedness, and needle-stick and occupational health. The third component focused on healthcare associated infections and consisted of three primary questions: 1 ) how to assess risk of infections at your institution; 2) if and what intervention strategies had been instituted; and 3) factors contributing to successes of HAI prevention. The forth component had two questions aiming to identify education needs: 1 ) do you feel the needs for more training; and 2) if so, select one type of training (i.e. training by specific subject; general conferences; advanced training provided by international experts; or observation in a hospital with robust infection control program) suitable for you.

\section{Data Management and Statistical Analysis}

Data was managed using Microsoft Excel (Microsoft Corp, Seattle, WA) and analyzed using Stata (Stata Corp, TX). It included descriptive analysis and analysis stratified by respondent's education category (nursing, medicine, and public health), level (associate, bachelor and post-graduate), and years of infection control experience $(\geq 5$ years, $3-5$ years, and $<3$ years). Logistic regression was conducted to evaluate significance of observed relationship. A $p$ value less than 0.05 was considered statistically significant.

\section{Results}

A total of 880 people from 32 provinces and autonomous regions (including Moocow) participated in the survey. Of 637 participants who reported number of beds in their hospitals, $60 \%$ worked in a hospital with greater than 500 beds. 
The most common professional education and training these respondents received was nursing (59.2\%), followed by clinical medicine $(31.6 \%)$, and public health $(8.8 \%)$. Individuals with bachelor degrees (requiring five-year education including internship) in Nursing and Medicine accounted for $29 \%$ and $21 \%$ of respondents, respectively. An additional $29 \%$ of respondents had a Nursing Associate degree (requiring three-year education including internship), and $9.2 \%$ of respondents had post-graduate education at Master $(7.6 \%)$ or Doctoral $(1.5 \%)$ level. Nearly half (45\%) of respondents had five or more years working experience as an ICP, and $11 \%$ of respondents had worked as an ICP for one year or less. The majority $(69 \%)$ of respondents were full-time ICPs.

Hand hygiene $(80.5 \%)$, prevention and control of MDROs (59.0\%), and outbreak management (52.5\%) were perceived as the most important infection control areas (Table I). This distribution remained unchanged in the stratified analysis by respondent's education category, level, and years of infection control experience. Overall, the perception was mostly built upon personal experience (63.2\%), followed by information obtained through continuing education (e.g. conferences, workshops) $(48.6 \%)$ and results of bi-annual prevalence studies $(44.7 \%)$ conducted in each hospital (Table I). Comparing individuals with bachelor or associate degree, those with post-graduate training were more likely to base their perception upon published literatures (Odds Ratio [OR]: 1.25, 95\% Confidence Interval $[\mathrm{Cl}]: 0.99-1.58 ; \mathrm{p}=0.06$ ) and personal experience (OR: 1.16; 95\% Cl: 0.92 1.46; $p=0.21]$. However the associations were not statistically significant.

When assessing risks of device associated HAls, surgical site infections, and MDROs, respondents continually relied on results of bi-annual prevalence study $(54.5 \%)$ conducted in each hospital, personal experience $(39.0 \%)$, and information obtained from continuing education $(34.5 \%)$. It was of note that $28.1 \%$ of respondents accounted for administrators' opinion during their risk assessment.

Intervention to reduce risks of device associated HAls and surgical site infections were commonly conducted $(83.0 \%)$. Education and training healthcare workers was the most frequently used strategy $(71.1 \%)$ followed by implementing recommendations published by the Chinese Ministry of Health (55.1\%). Fifteen percent of respondents had considered using the "bundle" approach (see Table I) established in United States. ${ }^{13-16}$ Seventeen percent of respondents reported either they had not conducted intervention before or had no knowledge on how to do intervention. There was a reverse relationship between conduct of intervention and years of ICP experience (OR: $0.71,95 \% \mathrm{Cl}: 0.59$ $-0.86 ; \mathrm{p}<0.001)$. Respondents viewed that key factors contributing to successes of interventions included clinical staff collaboration ( $81.5 \%$ ) followed by support from hospital leadership (61.0\%).

Overall, $17.5 \%$ of respondents reported that they perform active surveillance either to detect patients colonized with meticillin resistant Staphylococcus aureus (30.0\%), vancomycin resistant Enterococcus species $(17.7 \%)$, Extended-Spectrum $\beta$-Lactamases $(18.6 \%)$ or other significant MDROs $(12.9 \%)$ in their hospitals (Table II). In contrast, respondents listed barriers for active surveillance, which included lack of ICP resources for the coordination of surveillance related activities $(28.3 \%)$, lack of microbiology resources for testing $(33.5 \%)$, and lack of capacity for isolating patients with positive results (22.4\%).

These respondent's daily activities were nearly equally divided into data collection (13.6\%), staff education and training $(9.8 \%)$, prevention of disease transmission $(15.1 \%)$, infection identification $(8.2 \%)$, outbreak detection (6.8\%), feedback and communication $(8.8 \%)$, and other HAI related projects (12.3\%).

Ninety-six percent of respondents felt strongly that further training was needed. Of the four options given, most of the respondents favoured 'focused training by specific topics' (75.3\%) and 'visiting hospitals with successful infection control programs'.

\section{Discussion}

This was the first study that described characteristics of infection control professionals and status of infection control programs in China. Participants of the study worked in hospitals located in 32 of 34 provinces and autonomous regions in China and possessed a broad national representation. 
This study found that greater than $50 \%$ respondents received 5-year professional training in Nursing or clinical Medicine and an additional 29\% of respondents had 3-year training in Nursing. This finding was comparable to the proportion of $80 \%$ physicians and registered nurses reported in a national survey conducted among infection control professionals in the United States. ${ }^{5}$ Moreover, similar to finding of this U.S. survey, $50 \%$ of our respondents were experienced and had worked as an ICP for 5 years or longer. ${ }^{5}$

Of eight major infection control areas, respondents considered hand hygiene as the most important one. This concurred with findings from a previous survey conducted in a selected group of staff working in 25 key hospitals and public health agencies in China. Using a qualitative survey, investigators found that these individuals viewed hand hygiene as paramount important to effective infection control and had adequate knowledge about proper hand hygiene practices. ${ }^{17}$ Collectively these results suggested that infection control professionals in China were motivated to improve hand hygiene compliance. However, to achieving sustainable successes, these ICPs ought to adapt evidence-based approaches such as continuous monitoring and timely feedback. ${ }^{17}$

Prevention and control of MDROs was viewed as the second priority by infection control professionals. This finding reflected growing attentions on antibiotic management in China. In 2004, Chinese Ministry of Health introduced Antibiotic Guideline and required each hospital to form an antimicrobial stewardship. Despite these administrative efforts, the pattern of antibiotic use in individual hospitals remained unchanged from 2002 to $2006 . .^{18}$ It was estimated that $75 \%$ of patients with seasonal influenza were prescribed antibiotics, and nearly $80 \%$ of inpatients were prescribed antibiotics in China. ${ }^{19}$ This antibiotic prescription pattern was not only a threat to the health of Chinese, ${ }^{19,20}$ but also posed global concerns for the emergence and spread of MDROs worldwide. 10,11,20,21 In reorganization of this paramount demand for curtailing MDRO in China, we sought to assess ICPs' awareness on MDRO prevention. In response to the question "Does your hospital conduct routine active screening for MDROs among hospitalized inpatients?", $18 \%$ of the respondents reported such screening was conducted in their hospitals. However, given that active surveillance for the early detection of colonization remained a novel concept in China at the time of study, these respondents could have selected the answer because of the misinterpretation of monitoring MDRO infections as active surveillance. To heighten awareness and mend knowledge gaps among these ICPs, our study suggested two education approaches for consideration. First, given that over half of respondents indicated following intervention strategies recommended by the Chinese Ministry of Health, education could take place among policy makers so that evidence-based guidelines could be developed and implemented. The second approach was to provide in-depth or hands-on training to front line ICPs directly. This was strongly suggested by overwhelming responses in favour of more education by specific subjects.

Despite the publication of a compendium of strategies to prevent healthcare-associated infections ${ }^{22}$ and rich evidences suggesting the importance of adhering to evidence-based practices, ${ }^{13-16}$ education remained the primary strategy used by Chinese ICPs to reduce risks of HAls. Further studies were warranted to investigate ICP knowledge and attitude on evidence-based infection control practices. Although previous study suggested that conducting high quality local research is likely to be an effective way of getting research findings into practice in developing countries, ${ }^{23,24}$ studies ought to be conducted to explore the best avenue of bridging evidence and IC practice in China.

Similar to their peers in United States, ICPs in China were multi-tasked. Although most of their time was spent on surveillance related activities such as data collection and case finding, ${ }^{4,5}$ their responsibilities ranged from staff education, outbreak management, to occupational health.

Our study was strengthened by a large sample size and broad geographic representations. However we recognized that our study finding could be biased if attendees of these national conferences were selected based on characteristics such as roles or seniority in the department. The presence of this bias could further augment the demand for more education and handson trainings in this population. 
Table I. Responses to Questions related to Perceptions on Importance of Infection Control Areas and Preventing Healthcare Associated Infections

Questions and Options Given

Sub-categories $(\mathrm{N}=\mathbf{8 8 0})$

Select three infection control areas that are of the most importance:

Overall In Your Institution

Preventing device-associated infections

(CLABSI; VAP; UTI)

$42.5 \%$

$44.7 \%$

Preventing surgical site infection

$35.8 \%$

$28.4 \%$

Outbreak detection and prevention

$52.5 \%$

$47.0 \%$

Preventing transmission of multi-drug resistant organisms

$59.0 \%$

$68.3 \%$

Hand hygiene

$80.5 \%$

$75.5 \%$

Infection control in construction and renovation

$9.0 \%$

$8.5 \%$

Emerging infectious disease preparedness

Preventing needle stick and occupational exposures

$11.4 \%$

$10.9 \%$

Other, specify

$20.5 \%$

$15.5 \%$

Select evidence bases you used to rank the importance of infection control areas:

Trends of infection rates obtained in bi-annual prevalence study

$44.7 \%$

Annual surveillance data

$18.3 \%$

Personal experience

Medical literature reports

Opinions or instructions of hospital leadership

Media's attention

Up-to-date information obtained during training

or professional conferences

\begin{tabular}{lrr}
\hline Select evidence bases you used for risk assessment in your institution: & $\begin{array}{r}\text { Central Line } \\
\text { Associated } \\
\text { Bloodstream } \\
\text { Infections }\end{array}$ & $\begin{array}{r}\text { Surgical Site } \\
\text { Infections }\end{array}$ \\
\hline Trends of infection rates obtained in bi-annual prevalence study & $48.3 \%$ & $53.0 \%$ \\
\hline Annual surveillance data & $17.6 \%$ & $20.3 \%$ \\
\hline Personal experience & $46.8 \%$ & $36.8 \%$ \\
\hline Medical literature reports & $28.9 \%$ & $24.4 \%$ \\
\hline Opinions or instructions of hospital leadership & $5.7 \%$ & $5.6 \%$ \\
\hline Media's attention & $5.8 \%$ & $5.7 \%$ \\
\hline Up-to-date information obtained during training or professional & $39.5 \%$ & $34.2 \%$ \\
conferences & &
\end{tabular}


Select intervention measures, if any, you have implemented for

Central Line preventing infections

Associated

Bloodstream

Surgical Site

Infections

Infections

\begin{tabular}{lcr}
\hline No intervention & $4.5 \%$ & $3.4 \%$ \\
\hline I would like to do intervention, but don't know how & $12.0 \%$ & $8.4 \%$ \\
\hline Intervention using education and training to doctors and nurses & $71.3 \%$ & $70.9 \%$ \\
\hline Intervention using national guidelines & $52.5 \%$ & $57.6 \%$ \\
\hline Intervention based on hospital's experience & $4.4 \%$ & $7.2 \%$ \\
\hline Intervention using the "bundle" approach reported in literatures & $15.2 \%$ & $14.1 \%$
\end{tabular}

If intervention is implemented, select factors contributing to successes

Central Line for preventing infections

Associated

Bloodstream

Surgical Site

Infections

Mandate prevention of infections as an accreditation requirement

\begin{tabular}{ll}
$32.0 \%$ & $25.3 \%$ \\
\hline $66.8 \%$ & $55.2 \%$ \\
\hline $86.3 \%$ & $76.8 \%$ \\
\hline $28.3 \%$ & $23.1 \%$ \\
\hline
\end{tabular}

Support from hospital leadership

$5.1 \%$

$3.3 \%$

Table II. Responses to Questions related to Multi-drug Resistant Organisms

\section{Select the evidence base you used for risk assessment in your institution}

\begin{tabular}{rr}
$\begin{array}{r}\text { Number of } \\
\text { Responses }\end{array}$ & $\begin{array}{r}\text { Percentage of } \\
(\mathrm{N}=\mathbf{8 8 0})\end{array}$ \\
\hline
\end{tabular}

\begin{tabular}{lcr}
\hline $\begin{array}{l}\text { Trends of infection rates obtained in bi-annual prevalence } \\
\text { study }\end{array}$ & 548 & $62.3 \%$ \\
\hline Annual surveillance data & 176 & $20.0 \%$ \\
\hline Personal experience & 294 & $33.4 \%$ \\
\hline Medical literature reports & 273 & $31.0 \%$ \\
\hline Opinions or instructions of hospital leadership & 51 & $5.8 \%$ \\
\hline Media's attention & 36 & $4.1 \%$ \\
\hline $\begin{array}{l}\text { Up-to-date information obtained during training or professional } \\
\text { conferences }\end{array}$ & 317 & $36.0 \%$ \\
\hline
\end{tabular}




\begin{tabular}{lcc}
\hline \multicolumn{2}{l}{ If you have implemented routine active surveillance among inpatients, which organism is being actively } \\
screened & 264 & $30.0 \%$ \\
\hline Meticillin resistant Staphylococcus aureus & 156 & $17.7 \%$ \\
\hline Vancomycin resistant Enterococcus species & 164 & $18.6 \%$ \\
\hline Extended B-lactamase producing gram-negative rods & 155 & $17.6 \%$ \\
\hline Multi-drug resistant Acinetobacter baumannii & 157 & $17.8 \%$ \\
\hline Multi-drug resistant Pseudomonas aeruginosa & 29 & $3.3 \%$ \\
\hline Clostridium difficile & 45 & $5.1 \%$ \\
\hline If you have not implemented routine active surveillance, what are the barrier(s): & $7.3 \%$ \\
\hline Unknown if active surveillance can prevent infections & 64 & $28.3 \%$ \\
\hline Active surveillance is not necessary & 249 & $33.5 \%$ \\
\hline Lack of ICP resources for the coordination of surveillance & 295 & $22.4 \%$ \\
\hline related activities
\end{tabular}

\section{Conclusions}

This study described infection control professionals and status of infection control activities in China. Furthermore it identified three gaps that warranted immediate attention to advance practices in China. These gaps were lack of knowledge on common practice including active surveillance, lack of education on specific IC matters, and lack of evidencebased IC practice. Given that China has the largest population in the world, improving IC practices and thus reducing HAI associated burdens could shed light to the overall quality of care. In addition, since China has attracted growing number of visitors worldwide and international travelling has been accelerated by advanced transportation technologies, enhancing infection control programs in China had great potential to benefit the health of international communities at large.

\section{Acknowledgement}

Authors were thankful for Mr. Chikeung Shiu for his help with this project.

\section{Financial Disclosure}

Authors have no conflict of interest to disclose.

\section{Reference:}

1. Haley RW, Quade D, Freeman HE, Bennett JV. The SENIC Project. Study on the efficacy of nosocomial infection control (SENIC Project). Summary of study design. Am / Epidemiol 1980; 111(5): 472-485.

2. O'Boyle C, Jackson M, Henly SJ. Staffing requirements for infection control programs in US health care facilities: Delphi project. Am J Infect Control 2002; 30(6): 321-333. http:// dx.doi.org/10.1067/mic.2002.127930

3. Scheckler WE, Brimhall D, Buck AS, et al. Requirements for infrastructure and essential activities of infection control and epidemiology in hospitals: a consensus panel report. Society for Healthcare Epidemiology of America. Infect Control Hosp Epidemiol 1998; 19(2): 114-124. http://dx.doi. org/10.1086/647779

4. Stricof RL, Schabses KA, Tserenpuntsag B. Infection control resources in New York State hospitals, 2007. Am J Infect Control 2008; 36(10): 702-705. http://dx.doi.org/10.1016/j. ajic.2008.01.011

5. Stone PW, Dick A, Pogorzelska M, Horan TC, Furuya EY, Larson E. Staffing and structure of infection prevention and control programs. Am J Infect Control 2009; 37(5): 351-357. http://dx.doi.org/10.1016/j.ajic.2008.11.001

6. Nguyen GT, Proctor SE, Sinkowitz-Cochran RL, Garrett DO, Jarvis WR. Status of infection surveillance and control programs in the United States, 1992-1996. Am I Infect Control 2000; 28(6): 392-400. http://dx.doi.org/10.1067/mic.2000.110298

7. Ho PL, Tang XP, Seto WH. SARS: hospital infection control and admission strategies. Respirology 2003; 8 Suppl: S41-5. http:// dx.doi.org/10.1046/j.1440-1843.2003.00523.x

8. Lam WK, Zhong NS, Tan WC. Overview on SARS in Asia and the world. Respirology 2003; 8 Suppl: S2-5. http://dx.doi. org/10.1046/j.1440-1843.2003.00516.x 
9. Ngan Kee WD, Leung TN. Severe acute respiratory syndrome (SARS). Int J Obstet Anesth 2003; 12(3): 151-152. http:// dx.doi.org/10.1016/S0959-289X(03)00061-X

10. Muir A, Weinbren MJ. New Delhi metallo-beta-lactamase: a cautionary tale. J Hosp Infect 2010; 75(3): 239-240. http:// dx.doi.org/10.1016/j.jhin.2010.02.005

11. Kumarasamy KK, Toleman MA, Walsh TR, et al. Emergence of a new antibiotic resistance mechanism in India, Pakistan, and the UK: a molecular, biological, and epidemiological study. Lancet Infect Dis 2010; 10(9): 597-602. http://dx.doi. org/10.1016/S1473-3099(10)70143-2

12. Detection of Enterobacteriaceae isolates carrying metallobeta-lactamase - United States, 2010. MMWR 2010; 59(24): 750.

13. Pronovost P. Interventions to decrease catheter-related bloodstream infections in the ICU: the Keystone Intensive Care Unit Project. Am J Infect Control 2008; 36(10): S171 e1-5.

14. Pronovost $\mathrm{P}$, Needham $\mathrm{D}$, Berenholtz $\mathrm{S}$, et al. An intervention to decrease catheter-related bloodstream infections in the ICU. N Engl / Med 2006; 355(26): 2725-2732. http://dx.doi. org/10.1056/NEJMoa061115

15. Berenholtz SM, Pronovost PJ, Lipsett PA, et al. Eliminating catheter-related bloodstream infections in the intensive care unit. Crit Care Med 2004; 32(10): 2014-2020. http://dx.doi. org/10.1097/01.CCM.0000142399.70913.2F

16. Miller MR, Griswold M, Harris JM, et al. Decreasing PICU catheter-associated bloodstream infections: NACHRI's quality transformation efforts. Pediatrics 2010; 125(2): 206-213. http://dx.doi.org/10.1542/peds.2009-1382
17. Yuan CT, Dembry LM, Higa B, Fu M, Wang H, Bradley EH. Perceptions of hand hygiene practices in China. J Hosp Infect 2009; 71(2): 157-162. http://dx.doi.org/10.1016/j. jhin.2008.09.017

18. Zhang W, Liu X, Wang Y, et al. Antibiotic use in pulmonology wards of Chinese children's hospitals: 2002-2006. J Clin Pharm Ther 2009; 34(1): 61-65. http://dx.doi.org/10.1111/j.13652710.2008.01001.x

19. Zheng Y, Zhou, Z. The root causes of the abuse of antibiotics, harm and the rational use of the strategy. Hospital Management Forum (in Chinese) 2007; 123: 23-27.

20. Zhang R, Eggleston K, Rotimi V, Zeckhauser RJ. Antibiotic resistance as a global threat: evidence from China, Kuwait and the United States. Global Health 2006; 2: 6. http://dx.doi. org/10.1186/1744-8603-2-6

21. Heddini A, Cars O, Qiang S, Tomson G. Antibiotic resistance in China - a major future challenge. Lancet 2009; 373(9657): 30. http://dx.doi.org/10.1016/S0140-6736(08)61956-X

22. Yokoe DS, Mermel LA, Anderson DJ, et al. A compendium of strategies to prevent healthcare-associated infections in acute care hospitals. Infect Control Hosp Epidemiol 2008; 29 Suppl 1: S12-21. http://dx.doi.org/10.1086/591060

23. Page J, Heller RF, Kinlay S, et al. Attitudes of developing world physicians to where medical research is performed and reported. BMC Public Health 2003; 3: 6. http://dx.doi. org/10.1186/1471-2458-3-6

24. Page J, Heller RF, Kinlay S, et al. Where do developing World clinicians obtain evidence for practice: a case study on pneumonia. J Clin Epidemiol 2000; 53(7): 669-675. http:// dx.doi.org/10.1016/S0895-4356(99)00231-0 